\title{
Development and Evolution of the Pharyngeal Apparatus
}

Aude Frisdal ${ }^{1,2}$ and Paul A Trainor ${ }^{1,3,{ }^{*}}$

${ }^{1}$ Stowers Institute for Medical Research, Kansas City, MO, USA

${ }^{2}$ University Pierre and Marie Curie, Paris, France

${ }^{3}$ Department of Anatomy and Cell Biology, University of Kansas Medical Center, KS, USA

\section{Abstract}

The oral or pharyngeal apparatus facilitates the dual functions of respiration and feeding. It develops during embryogenesis from transient structures called pharyngeal arches, which comprise a reiterated series of outgrowths on the lateral side of the head. The pharyngeal arches and their segmental arrangement are highly conserved throughout evolution from invertebrate chordates such as amphioxus, through to vertebrate agnathans including avians, squamates and mammals. The structural organization of the pharyngeal arches is also highly conserved and involves contributions from each of the three primary endoderm, mesoderm and ectoderm germ layers. The endoderm is particularly important for pharyngeal arch formation and segmentation and also plays a critical role in tissue specific differentiation. The ectoderm gives rise to neural crest cells (NCC) which provides an additional layer of complexity to pharyngeal arch development and differentiation in vertebrates compared to invertebrate chordates that do not possess NCC. Collectively the pharyngeal arches give rise to much of the neurovasculature and musculoskeletal systems in the head and neck. The complexity of development renders the pharyngeal apparatus prone to perturbation and subsequently the pathogenesis of birth defects. Hence it is important to understand the signals and mechanisms that govern the development and evolution of the pharyngeal complex.

\section{Introduction}

The oral or pharyngeal apparatus serves the dual functions of respiration and feeding in many species in the animal kingdom. In humans, the mouth, nose and associated sinus, together with the pharynx which is connected to the larynx and trachea, form the upper respiratory tract. The pharynx, also connects to the esophagus, caudal to the larynx as part of the upper digestive tract. Thus, the mouth and the pharynx serve the essential functions of both feeding and respiration, and therefore it is essential they form correctly during embryogenesis. One-third of congenital disorders affect the head and neck ${ }^{1}$ and several syndromes such as DiGeorge syndrome ${ }^{2}$ or Treacher Collins syndrome ${ }^{3}$ encompass malformations that affect the structure and function of the oral complex. Hence it is

*Author for Correspondence: Paul A Trainor, Investigator, Stowers Institute for Medical Research, 100 East $50^{\text {th }}$ Street, Kansas City, MO 64110, USA, pat@ stowers.org, Phone: +1 816926 4414, Fax: +1 8169262051. 
important to understand the molecular mechanisms and cellular processes that govern the establishment and development of the pharyngeal complex.

The pharyngeal complex forms during early embryonic development and commences as a reiterated series of outgrowths on the lateral side of the head called pharyngeal arches (PAs) (fig1 and 2a). Together with a medial outgrowth called the fronto-nasal prominence (FNP), these transient morphological structures collectively give rise to the face and the neck of an adult organism. Anatomically, the structure and organization of the PAs has been highly conserved throughout vertebrate evolution. Agnathan (jawless) fish such as lamprey possess PAs and, even invertebrate chordate species such as amphioxus exhibit pharyngeal segmentation of the head. These PAs give rise to the gills, the respiratory organs for aquatic species and are therefore referred to as branchial arches in aquatic species.

In this review we focus (i) on the importance of the PAs in formation of the face, especially the jaw and the neck; (ii) highlight emerging evidence of a role for the endoderm in their formation and differentiation; (iii) and discuss the mechanisms underpinning PA development and evolution.

\section{1- PA Development}

The human head and face are anatomically complex structures that form during embryogenesis, from the FNP and the PAs. The FNP gives rise to the forehead and the nose, while the paired PAs give rise to the lower face (the jaw), the neck and part of the upper thorax.

The number of PAs is species-dependent and may vary from 4 to 9. For example, in mammals there are 5 pairs of PAs, numbered 1, 2, 3, 4 and 6 (as the fifth PA disappears almost as soon as it forms), while in zebrafish there are $7 \mathrm{PAs}^{4}$. However in each case they develop sequentially in a cranial to caudal manner and are separated by a cleft and pouch which appose each other. The $1^{\text {st }} \mathrm{PA}$ which is also called the mandibular arch, appears first followed by the $2^{\text {nd }} \mathrm{PA}$ or hyoid arch, then the others one by one. In fish, the $3^{\text {rd }}$ to $7^{\text {th }} \mathrm{PAs}$ are called gill arches. For aquatic species, the number of PAs is usually higher since the gills are relatively inefficient filters. The basic structure of each PA is the same. Externally, the PAs are composed of ectoderm which forms the pharyngeal cleft or groove. Internally, the PA are lined with endoderm which forms the pharyngeal pouch (fig.1). At the junction that separates the different PAs, the endoderm contacts the ectoderm by an active movement called out-pocketing.

Between the endoderm and ectoderm epithelia is a mesenchymal core. In invertebrates such as amphioxus, the mesenchymal core is composed of mesoderm. In vertebrates, the mesenchymal core is composed of both mesoderm and neural crest cells (NCC). NCC are a multipotent stem cell population that delaminate from the neural plate via an epithelial to mesenchymal transformation ${ }^{5}$, and migrate in discrete segregated streams, colonizing each PA (fig.1 and fig.3a). Collectively, these four tissue types: endoderm, mesoderm, ectoderm and NCC interact to give rise to the skeletal, muscular, vascular and nervous system elements of the head and the neck of vertebrates. 
Briefly, the endoderm gives rise to viscera including the thymus, thyroid and parathyroid glands which comprise part of the endocrine system. The mesoderm gives rise to endothelial cells and myoblasts, the progenitors of the vasculature and musculature respectively (fig. $3 \mathrm{~b}$ and c). The pharyngeal vascular system comprises a reiterated series of pharyngeal arch arteries (PAAs) that are present within each PA (fig.1). The ectoderm can be subdivided into a lateral domain of surface ectoderm and a medial domain of neural ectoderm which gives rise to the skin and nervous system respectively. Furthermore, the dorsal neural ectoderm that forms a boundary with the surface ectoderm, also generates NCC that migrate into the FNP, contributing to bones and connective tissue of the face and skull $^{6}$. The NCC that colonize the PAs give rise to the bones of the jaw, the three small bones of the middle ear (malleus, incus and stapes) as well as the cartilages of the neck. They also contribute to the formation of the teeth, as NCC give rise to the dentin secreting odontoblasts and pulp. In contrast, the enamel is produced by oral ectoderm derived ameloblasts. Similar to the teeth, the peripheral nervous system is also of dual cellular origin. NCCs generate sensory neurons and glia that integrate with surface ectoderm derived cranial sensory placode generated neurons. NCC also form mural cells, the pericytes and smooth muscle cells that surround endothelial cells within the great blood vessels of the head, and parts of the neck and upper thorax.

\section{2- PA Differentiation}

\section{Skeletal derivatives: the role of NCC in bone formation in the head and neck}

In mammalian adults, the jaw is composed of the maxilla and dentary bones, which define the upper and lower jaw respectively. These two bones articulate to facilitate mastication, respiration and vocalization. The jaw is formed during embryogenesis primarily from the $1^{\text {st }}$ PA, which is composed of two paired processes known as the maxillary and mandibular prominences. The maxillary process give rise to the upper jaw and the palate, while the mandibular process give rise to the lower jaw. Fate mapping and lineage tracing in avians, fish and mice have revealed that the bones that comprise the upper and lower jaw are derived from NCC that primarily colonize the $1^{\text {st }} \mathrm{PA}^{7-11}$ (fig.2b, 3a). However, recent lineage tracing analyses in avian species has indicated that part of the upper jaw comes from facial prominences rostral to the the $1^{\text {st }} \mathrm{PA}{ }^{12}$.

During embryogenesis, two types of ossification, intramembranous and endochondral, underpin formation of the skull and facial skeleton. In the intramembranous ossification process, NCC differentiate directly into functional osteoblasts ${ }^{13}$, which induce an osteoid matrix that becomes a center of ossification. The maxilla and dentary bones undergo direct ossification of NCC and are therefore classified as membrane or dermal bones.

In contrast, during endochondral ossification, $\mathrm{NCC}$ initially form a cartilage template, which is subsequently replaced by osteoblasts. Two such cartilages derived from the $1^{\text {st }} \mathrm{PA}$ are Meckel's cartilage, in the mandibular prominence and palatopterygoquadrate, in the maxillary prominence. The malleus which is derived from Meckel's cartilage, together with the anterior ligament of the malleus and the sphenomandibular ligament, collectively contribute to the temporomandibular joint. The palatopterygoquadrate gives rise to the alisphenoid, a bone that is part of the orbital wall, and it also gives rise to the incus. 
Reichert's cartilage of the $2^{\text {nd }} P A$ forms the third middle ear bone known as the stapes (fig. $2 b)$.

In the neck, the larynx and pharynx are composed of skeletal elements that are, in anterior to posterior order, the hyoid bone, the thyroid cartilage and the cricoid cartilage. The hyoid bone facilitates tongue movement and swallowing, and the body of the hyoid bone is derived from NCC of the $3^{\text {rd }} \mathrm{PA}$. It is attached to the styloid process of the temporal bone by the stylohyoid ligament, and is derived from Reichert's cartilage ( $\left.2^{\text {nd }} \mathrm{PA}\right)$. The thyroid cartilage protects the vocal cords and serves as an attachment for the laryngeal muscles. It derives from NCC of the $4^{\text {th }}$ PA. Finally, the cricoid is a ring of cartilage surrounding the trachea, which supports the ligament and muscles involved in opening and closing the airway, as well as producing sound. The cricoid comes from NCC of the $6^{\text {th }} \mathrm{PA}$. (fig. $2 \mathrm{~b}$ and table 1 ).

\section{Vasculature: the role of mesoderm and NCC in formation of blood vessels}

The vasculature comprises a network of vessels that facilitates blood circulation throughout the entire organism. Blood circulation serves several roles, it brings oxygen and nutrients to organs through the arterial system, and it removes waste products through the venal system. The vasculature regulates body temperature and also plays a role in immune defense by transporting immune cells (such as leukocytes or granulocytes). The vasculature is the first organ system to develop during embryogenesis. It is essential for normal development and undergoes considerable remodeling in association with growth and maturation of the organism.

The left and right dorsal aortae are the first major blood vessels to form in the embryo. They lie along the anterior-posterior axis of the embryo and connect to the heart and umbilical arteries. The PAAs form in concert with the PAs in a cranio-caudal gradient ${ }^{14}$ and connect the heart to the existing dorsal aorta. The PAAs comprise tubes of endothelial cells that are derived from mesoderm. They form through the process of vasculogenesis, which is defined as de novo formation of blood vessel from endothelial cell precursors known as angioblasts. To maintain vessel stability and quiescence, mural cells are recruited along the endothelial tube. These cells are pericytes and smooth muscle cells and are derived from NCC ${ }^{15}$. Although most of the smooth muscle cells in the heart field are derived from NCC, a small population is derived from mesoderm. Furthermore, the smooth muscle cells of the coronary arteries are thought to have a pro-epicardial origin which is derived from lateral plate mesoderm ${ }^{16,17}$.

The primitive vasculature is initially symmetrical but subsequently undergoes asymmetric remodeling to form the mature, definitive and functional vascular system seen in the adult ${ }^{18}$. The remodeling involves apoptosis mediated regression of the $1^{\text {st }}$ and $2^{\text {nd }}$ PAAs. The $1^{\text {st }}$ PAA however, still contributes to a small portion of the maxillary artery that supplies the deep tissues of the face. The $2^{\text {nd }}$ PAA gives rise to the stapedial artery, which irrigates the stapedial muscle of the inner ear. The $3^{\text {rd }}$ PAA is devoted to formation of the carotid system. It gives rise to the left and right common carotid arteries that irrigate the head and neck. The common carotid artery bifurcates into the internal and external carotids. The proximal portion of the internal carotid is an extension of the common carotid arteries while the distal portion is derived from the dorsal aorta. The external 
carotid arteries sprout $d e$ novo from the common carotid arteries by angiogenesis. The $4^{\text {th }}$ PAA gives rise to the pulmonary artery and the definitive aortic arch. The $6^{\text {th }}$ PAA first give rises to the pulmonary trunk, a blood vessel that emerges from the right ventricles, but which is remodeled asymmetrically. While the right $6^{\text {th }}$ artery disappears, the distal portion of left $6^{\text {th }}$ PA artery forms the ductus arteriosus (fig.4 and table 2). This artery is essential for fetal blood circulation as it shunts blood from the pulmonary trunk to the descending aorta. At birth, as the lungs start their function, the ductus arteriosus closes allowing circulation through to the lungs to oxygenate the blood that subsequently reaches the systemic circulation of the new born.

\section{The peripheral nervous system (PNS) is derived from neural ectoderm, non neural ectoderm, and NCC}

The PNS is an essential system that carries information between the body and the central nervous system through a complex network of nerves. For example, when pain is sensed, this information is relayed to the brain through sensory nerves and returns through the motor system to control movement of the body and protect the organism. The PNS is formed from three primary tissues: neural ectoderm, NCC and ectodermal placodes (fig. $3 \mathrm{~d}$ and e). Placodes are thickened regions of epithelial cells within the surface ectoderm of the embryo. In total there are 7 cranial placodes named adenohypophyseal, lens, olfactory, trigeminal otic, geniculate, petrosal and nodose.

The PNS comprises multiple elements including: (i) cranial nerves (neurons, axons and myelin) and ganglia (neuronal cell bodies and their nursing cells or Schwann cells), (ii) spinal nerves and ganglia, (iii) autonomic nerves and ganglia and (iv) enteric nerves and ganglia. The latter three systems constitute the trunk ganglia. NCC give rise to the all peripheral glia (Schwann cells) and neurons (autonomic neurons and sensory neurons) in the trunk.

In humans, there are 12 pairs of cranial nerves. They are: the Olfactory n. (I), Optic n. (II), Oculomotor n. (III), Trochlear n. (IV), Trigeminal n. (V), Abducens n. (VI), Facial n. (VII), Vestibulocochlear n. (VIII), Glossopharygeal n. (IX), Vagus n. (X), Accessory n. (XI) and Hypoglossal n. (XII). These cranial nerves are derived from both NCC and ectodermal neurogenic placodes, each of which provides neurons to the cranial nerves. The supporting cells (Schwann cells) of all cranial nerves are however all derived from NCC.

Among the 12 pairs of cranial nerves, four invade the PA to innervate muscles derived from the mesoderm core of the corresponding PA. The trigeminal (V), facial (VII), glossopharyngeal (IX) and Vagus (X) invade the $1^{\text {st }}, 2^{\text {nd }}, 3^{\text {rd }}$ and $4^{\text {th }} \mathrm{PA}$ respectively (fig. 2c). The trigeminal comprises three branches, the ophthalmic nerve (V1), which provides sensory input to the eye muscles, and the maxillary (V2) and the mandibular nerves (V3) that innervate the maxillary and mandibular prominences respectively. The trigeminal nerve is formed from anterior hindbrain derived NCC that integrate with the trigeminal placode. The facial nerve is formed from mid hindbrain derived NCC together with the $1^{\text {st }}$ epipharyngeal placode (geniculate). The glossopharyngeal nerve is derived from caudal hindbrain derived NCC and the $2^{\text {nd }}$ epipharyngeal placode (petrosal). Finally, the vagus nerve is derived from trunk NCC and the $3^{\text {rd }}$ epipharyngeal placode (nodose). 


\section{Muscle derivatives and their innervation}

The muscles of the face control facial expression, mastication, and movement of the eyes and lips. They are derived primarily from the mesodermal cores of the corresponding PA. In adults, the muscles of the face can be categorized by their function. For example, muscles that have a role in mastication are derived from the $1^{\text {st }} \mathrm{PA}$ mesoderm, while the muscles that govern facial expression are derived from $2^{\text {nd }} \mathrm{PA}$ mesoderm. The pharynx is surrounded by 2 layers of muscle, an external layer that is derived from $4^{\text {th }} \mathrm{PA}$ mesoderm and an internal layer that is derived from $6^{\text {th }}$ PA mesoderm (fig.2d).

The muscles of mastication are innervated by the maxillary branch of the trigeminal nerve (V2) and include the Masseter that is attached to the zygomatic process and to the zygomatic arch of the maxilla and the lateral surface of mandible. The temporalis is a large muscle that attaches the temporal bone and the coronoid process of mandible. Together these two muscles allow elevation of the mandible and stabilize it during mastication. The lateral and medial pterygoid muscles act synergistically with the masseter and facilitate depression of the mandible (or the chin). They also allow for lateral movement during chewing. Finally, the anterior belly of the digastric muscle acts to open the jaw (while the temporalis and masseter are relaxed) and helps during swallowing via insertion into the mandible and hyoid. The posterior belly of the digastric is derived from $2^{\text {nd }} \mathrm{PA}$ mesoderm, and inserts into the temporal bone and mastoid process. Finally, the mylohyoid muscle forms the floor of the oral cavity and it elevates the hyoid and tongue during swallowing. This cluster of muscles is innervated by the maxillary branch of the trigeminal nerve (V2) (table 3).

The muscles of facial expression are innervated by the facial nerve (VII). The risorius and zygomaticus (minor and major) muscles are responsible for smiling. The orbicularis oris muscle encircles the mouth and helps with lip movements. The orbicularis oculi encircles the eyes and facilitates winking. Despite its role in mastication and sucking, the buccinator, located in the cheek, is derived from mesoderm of the $2^{\text {nd }} \mathrm{PA}$ as well.

In the neck, the stylopharyngeus is a small muscle that forms the internal layer of the pharynx and helps to elevate the pharynx and the larynx during swallowing and speaking. This muscle is the only one that is derived from the $3^{\text {rd }} \mathrm{PA}$ mesoderm and it is innervated by the glossopharyngeal nerve (IX).

The superior, middle and inferior constrictors form the external muscular layer of the pharynx and are derived from the $4^{\text {th }} \mathrm{PA}$, as well as the cricoid and the levator veli palatine. They act to constrict the walls of the pharynx during swallowing. Derived from the $6^{\text {th }}$ PA mesoderm, the intrinsic muscles of the larynx help with respiration and phonation (the movement of vocal cords to produce sound). They are each innervated by the vagus nerve $(\mathrm{X})$ (table 3$)$.

\section{Sensory organs and their innervation}

The tongue is a particular muscle that manipulates food during mastication, perceives taste, and facilitates phonetic articulation. Its musculature derives from the mesoderm of 3 
different PAs: $1^{\text {st }}$ PA mesoderm forms the body of the tongue, $2^{\text {nd }}$ PA mesoderm is responsible for the formation of the midtongue and $3^{\text {rd }}$ PA mesoderm forms the root. The neuronal component of the tongue derives from NCC. Innervation of the anterior $2 / 3$ of the tongue comes from the lingual (mandibular division of the trigeminal nerve V3) and chorda tympani (branch of the facial VII) nerves. The posterior $1 / 3$ of the tongue is innervated by the glossopharyngeal nerve (IX).

The ear is important for balance and hearing and it is derived in part from the otic vesicle which forms dorsal to the $2^{\text {nd }}$ and $3^{\text {rd }}$ PAs. The pharyngeal pouch and cleft that separates the $2^{\text {nd }}$ and $3^{\text {rd }}$ PAs are crucial for formation of the external and middle ear. The pouch (endoderm) gives rise to the tubotympanic recess, the epithelium of the tympanic cavity, and the Eustachian tube that links the nasopharynx to the middle ear. In addition, the first pharyngeal pouch also gives rise to the tympanus, which defines the boundary of the middle ear. In contrast, the pharyngeal cleft (ectoderm) gives rise to the external auditory canal (table 4). The vestibulocochlear nerve (VIII) is derived from the otic placode and innervates the developing inner ear.

\section{3- Formation and Evolution of the Pharyngeal Apparatus}

The origin of the pharyngeal apparatus can be traced during evolution as far back as the cephalochordates (fig.5). For example, in amphioxus, an invertebrate aquatic species (and thus not possessing NCC), segmentation can be observed in the embryonic head, which is analogous to the PAs of vertebrates ${ }^{19}$. The amphioxus respiratory system consists of perforations at the contact points between the endoderm and ectoderm that facilitate filtration of water for feeding and respiration. These contact points are formed by outpocketing of the endoderm that evaginates to reach the ectoderm. This active movement is responsible for delimiting each segment ${ }^{20}$. Thus out-pocketing of the endoderm is an important conserved event that initiates the segmental patterning of the PAs in invertebrates and in vertebrates.

Evolutionarily, NCC are thought to be a cell type characteristic of vertebrates. Within this group, some species such as lamprey are characterized by the absence of a jaw which makes them an interesting model with which to study the pharyngeal region. Lampreys possess NCC and PAs but are agnathans (jawless vertebrate) that belong to the cyclostomes, which are characterized by a round mouth. Lampreys have a toothed and tunnel-like mouth that facilitates grabbing prey and sucking their blood which is filtered through the gills. In lamprey, the $1^{\text {st }}$ PAs gives rise to a rod of cartilage that fuses to form an unjointed branchial basket ${ }^{21}$. In gnathostomes, (jawed vertebrates), $1^{\text {st }} \mathrm{PA}$ differentiation has undergone considerable modification to form a jaw, with dorsoventral regionalization and articulation by a joint.

A "hinge and cap" model has been proposed to mechanistically describe development of the variety of jaws observed in animal kingdom. According to this model, the upper and lower jaws can be viewed as two polarized units that articulate 22 and furthermore they can be classified in two distinct groups: (i) the non-mammalian jaw, where articular and quadrate elements (homologs of the incus and malleus) form the articulation; and (ii) the mammalian 
jaw, where the incus and malleus make an articulation but the force bearing articulation is conveyed by the squamosal and dentary elements. The increased musculoskeletal complexity of the mammalian jaw reflects the transition from an aquatic filtering lifestyle to a more land dwelling predatory lifestyle. Furthermore, this lifestyle transition was also associated with the transformation of gills to lungs and was accompanied by a reduction in the number of caudal pharyngeal or branchial segments in avians, reptiles and mammals, compared to fish. In addition, this transition was also accompanied by creation of an air chamber in the middle ear to conduct sound. The three ossicles within the middle ear have undergone considerable transformation. In fish, Meckel's cartilage forms part of the lower jaw, while in mammals it forms the malleus. The hyomandibular bone present in fish has been transformed from a suspensory element, into a supporting element of the skull, the stapes $^{23}$. However, studies in cartilaginous fish and bony fish have illustrated the homology of the dorsal and ventral skeletal elements of the mandibular, hyoid and gill arches to the skeletal elements of the mammalian upper and lower jaw. This homology has been confirmed through conserved expression of $D l x$ genes, which play a predominant role in establishing the polarity and identity of the PAs ${ }^{24}$.

\section{The endoderm as an organizer of the pharyngeal apparatus}

It was once prominently thought that NCC were essential for PA formation and patterning. However, NCC ablation experiments performed in avian embryos have demonstrated that PAs form even in absence of $\mathrm{NCC}^{25}$. Furthermore, mouse genetic mutants in which specific streams of NCC are absent, also exhibit normal PA formation and basic patterning ${ }^{26}$. Collectively, this challenged the notion that $\mathrm{NCC}$ were required for the initial formation and patterning of the PAs. Consistent with this idea, amphioxus exhibit branchial segmentation indicating that pharyngeal segmentation preceded the appearance of NCC. Thus NCC are not necessary for PA formation.

Filtration in amphioxus is facilitated by perforation at contact points between the endoderm and ectoderm. Therefore it is the out-pocketing of endoderm that is critical for respiratory and feeding functions, and this has remained a conserved integral component of PA development in both invertebrates and vertebrates. In support of this idea, the zebrafish mutant vgo, which carries a mutation in $t b x l$, a transcription factor that is expressed in endoderm, does not form proper endodermal pouches and subsequently exhibits caudal pharyngeal arch agenesis and defects in cartilage formation ${ }^{27}$. The same is also true in TbxI mutant mice ${ }^{28}$. This suggests the endoderm is not only required for pharyngeal arch formation but also for pharyngeal arch differentiation. Consistent with this idea, transplantation of wild-type endodermal cells into the PAs of vgo/tbxl mutant zebrafish can rescue cartilage formation. Similarly, endoderm ablation experiments in avian embryos also result in agenesis of cartilages of the head, including Meckel's, quadrate and articular cartilages, and can be restored through endoderm xenografts in quail/chicken chimeras ${ }^{29}$. These experiments demonstrate the importance of the endoderm in PA formation, and differentiation of the NCC-derivative skeleton ${ }^{27}$.

Retinoic acid (RA), the active form of vitamin A, is a diffusible morphogen that is important for patterning many tissues along the antero-posterior axis of embryos including the 
pharyngeal arches. Mice mutant for Rdh10 or Aldhla2, the two key enzymes responsible for the oxidation of vitamin A (retinol) to retinal and then to RA respectively, both exhibit defects in $3^{\text {rd }}$ to $6^{\text {th }} \mathrm{PA}$ formation ${ }^{30}$ 31. Interestingly, in avian models of vitamin A deficiency (and thus deficiency for endogenous RA), Tbxl expression in the ectoderm was decreased demonstrating that RA regulates the expression of $t b x l^{32}$. Therefore, RA signaling is required for caudal endodermal pouch segmentation, and furthermore the pharyngeal pouch endoderm is very sensitive to the levels of RA ${ }^{33}$. However, while RA is required for endodermal pouch formation and thus pharyngeal segmentation, retinoid signaling is not required for specification of the pharyngeal pouch endoderm along the anterior-posterior axis ${ }^{33}$.

Fibroblast Growth factor (Fgf) signaling is also known to play a key role in endoderm pouch formation and differentiation. In wild-type zebrafish, clusters of endodermal cells migrate laterally to form the pharyngeal pouches. However, in zebrafish mutant for both $f g f 3-/$ - and fgf8-/-, endodermal cells are present but their migration is disorganized resulting in a failure of the pharyngeal pouches to form which manifests as a fusion of the PAs ${ }^{34}$. These alterations in pouch development correlate with severe cartilage formation defects ${ }^{34}$. Although the cartilages are derived from NCC, signaling from the endoderm is needed to induce NCC to form cartilage. This is mediated at least in part via fibroblast growth factors such as $f g f 3$ and $f g f 8$, which are expressed in the endoderm, together with fgf receptors such as $f g f r l$ which is expressed in NCC. Consistent with data in zebrafish, a hypomorphic Fgfrl mutant mouse also exhibits impaired PA formation and development ${ }^{35}$.

A recent study in lamprey revealed evolutionary conserved roles for Fgf signaling in pharyngeal segmentation. In lamprey, $f g f s$ are expressed in the endoderm while the $f g f r$ is expressed in NCC. Incubation of lamprey embryos in an inhibitor of $f g f r$, resulted in loss of pharyngeal pouch formation, and agenesis of pharyngeal derived cartilages. Therefore, the results obtained in lamprey are consistent with results obtained in others species, indicating that the role of Fgf signaling in endodermal pouch formation and skeletogenesis is highly conserved throughout vertebrate evolution ${ }^{36}$.

Thus the endoderm is an important organizer of the pharyngeal region. It initiates segmentation in the head region by undergoing evagination to reach the ectoderm in a process termed outpocketing. This outpocketing of endoderm is central to PA formation and is regulated in part through $T b x l$ and RA signaling. Furthermore, pharyngeal endoderm is a source of Fgf signaling and interactions between endoderm and NCC facilitate formation and development of NCC-derived cartilages.

Wnt signaling may also be a critical driver of endodermal pouch formation and pharyngeal segmentation. Recently, wnt1 $1 \mathrm{r}$ and wnt $4 a$, which are respectively expressed in the head mesoderm and ectoderm of zebrafish embryos, were shown to play distinct roles in the reiterated formation of pharyngeal pouches ${ }^{37}$. Time lapse imaging in combination with Wnt signaling mutants suggest that Wnt signaling governs two separate events. Initially, wnt1 $1 r$ and $\mathrm{racl}$ destabilize the endodermal epithelium to promote the lateral movement of pouchforming cells. Subsequently, wnt $4 \mathrm{a}$ and cdc 42 signaling induces the rearrangement of pouch cells into bilayers through restabilizing adherens junctions ${ }^{37}$. How this newly identified, 
Wnt mediated, dynamic control of epithelial morphology intersects with Fgf or RA signaling remains to be examined. However, in the future it will be important to explore these interactions and also to determine whether Wnt mediated regulation of the pharyngeal endoderm represents an evolutionary conserved mechanism underpinning pharyngeal formation and segmentation.

\section{4- Regulation of PA Identity and Development}

Many different gene families play important roles in PA patterning. Here we focus on the Dlx and Hox genes, which are the primary regulators of anterior-posterior and dorso-ventral patterning of the PAs.

\section{A DIx code for PA Patterning}

Dlx genes are homeodomain transcription factors that establish pattern and polarity of the $1^{\text {st }}$ PA, and they are also important for regulating the identity of NCC-derived bones of the face. In mammals, there are $6 D l x$ genes, and they exhibit nested domains of expression in the PAs which is critical for specifying the identity of the upper and lower jaw. The six $D l x$ genes are conserved and arose as a result of cis duplication (first degree paralogues $D l x l$ and $D l \times 2$ ) and trans duplication (second degree paralogues Dlxl, Dlx6 and Dlx4 (and Dlx 2, 5, 3)) during evolution ${ }^{38}$. In mouse the six $D l x$ genes are expressed in the ectomesenchyme of the pharyngeal arches. Cartilaginous fish like skate and shark, and bony fish like paddlefish also possess $6 d l x$ genes similar to mammals, however, only one $d l x$ gene has been found in amphioxus 24 .

Targeted single and compound deletions of $D l x 1$ and $D l x 2$ revealed that these two genes are specifically required for proximal-distal identity of the $1^{\text {st }} \mathrm{PA}$. Mouse $D l x 1$ and $D l x 2$ are broadly expressed in the mandible and maxillary prominences of the $1^{\text {st }} \mathrm{PA}$, as well as in the $2^{\text {nd }}$ PA (fig.6). Dlxl-/- mutant mice exhibit a mild phenotype with a small stapes and alisphenoid bones. In contrast, Dlx2-/- mutants display more extensive defects in proximal skeletal elements derived from the $1^{\text {st }}$ and $2^{\text {nd }}$ PAs such as the alisphenoid, incus and stapes. More distal elements such as the malleus, mandible and the Meckels' cartilage were apparently unaffected. Dlxl/2-/- double mutant mice were phenotypically similar to the Dlx2-/- mutant ${ }^{39} 40$ (table 5). Taken together these results demonstrate that $D l x 2$ primarily, but also $D l x l$, are required for proper differentiation of the proximal structures that are derived from the $1^{\text {st }} \mathrm{PA}$.

Dlx5 and Dlx6 are expressed in nested domains within the Dlxl and $D l x 2$ expression territories (fig.6). Targeted deletion of Dlx5 in mice leads to defects of the lower jaw. Meckel's cartilage is shortened and dysmorphic in particular ${ }^{41}$. Interestingly, Dlx5/6-/double mutant mice exhibit an absence of Meckel's cartilage, and interestingly, vibrissae (mouse whiskers) are distributed symmetrically on the upper and lower jaw. These phenotypes reflect a transformation of the lower jaw to upper jaw 42,43 (table 5). Consistent with this idea, the shape of the maxillary and mandibular prominences are identical during embryogenesis. This suggests that upper jaw fate may represent a default state and that lower jaw fate is controlled by $D l x 5 / 6$ activity. 
Little is known concerning Dlx3/4 genes and their involvement in PA patterning. Dlx3-/mutants die at E10.5 due to placental failure, however no PA phenotype has been described $^{44}$. A Dlx4 knock out has not yet been reported.

Interestingly, endothelin $(E d n)$ signaling also regulates PA patterning and is an upstream regulator of $D l x$ gene activity. In mouse, chick and zebrafish, $E d n l$ is expressed in the ectoderm, core paraxial mesoderm and endodermal pouches, whereas its receptor Ednra is expressed in all $\mathrm{NCC}^{45,46}$. Both Ednl and Endra mutant mice each exhibit a phenotype that is similar to Dl $x 5 / 6-/$ - mutants, in the form of a small mandible, and agenesis of Meckel's cartilage and the hyoid bone, reflecting a homeotic transformation of the lower jaw to an upper jaw identity 47,48 . Inactivation of endothelin signaling in avian embryos also elicits a similar phenotype ${ }^{49}$. Conversely, ectopically overexpressing Ednl in the maxillary prominence induces an ectopic dentary bone (mandible) in the maxillary region, demonstrating that the upper jaw adopted a lower jaw identity ${ }^{50}$ (table 5). Ednl and its receptor Ednra regulate $D l x 5 / 6$, which in turn induces downstream targets specific to distinct proximodistal regions with the $1^{\text {st }}$ PA. Hand 2 for example, is expressed in the mediodistal region of the mandibular prominence ${ }^{51}$ and targeted deletion of a specific enhancer of Hand 2 in NCC of the $1^{\text {st }}$ and $2^{\text {nd }}$ PA leads to mandibular hypoplasia, ${ }^{52}$ mimicking the Dlx5/6 mutant homeotic transformation phenotype. Interestingly, Hand2 also acts in a feedback loop that downregulates Dlx5/6 in the most distal part of the mandibular region ${ }^{53}$. Therefore, $1^{\text {st }}$ PA patterning and consequently, upper and lower jaw formation, are regulated primarily via an $E d n / D l x / H a n d$ signaling axis. This signaling mechanism has been validated in mouse, avian and aquatic models as well as in humans with auriculocondylar syndrome ${ }^{54}$.

\section{A Hox code for Anterior-Posterior Patterning}

In insects and vertebrates, Hox genes play a key role in body plan organization along the anterior-posterior axis 55 . The Hox genes are organized in clusters, and through a process known as co-linearity, the spatio-temporal expression of these genes controls segmentation and PA identity in the head. Hox genes are not expressed in the $1^{\text {st }} \mathrm{PA}$, however, they are expressed in the NCC of $2^{\text {nd }}$ to $6^{\text {th }}$ PAs. In general, each PA is under the control of one Hox group, such that the Hox 2 group governs $2^{\text {nd }} \mathrm{PA}$ development, the Hox3 group regulates $3^{\text {rd }}$ PA patterning, and the Hox 4 group patterns the $4^{\text {th }} \mathrm{PA} 56,57$ (fig.6).

Mice mutant for Hoxa2 die perinatally and exhibit duplications of $1^{\text {st }}$ PA derived elements in the place of $2^{\text {nd }} \mathrm{PA}$ derived structures ${ }^{58,59}$. Conversely, overexpression of Hoxa 2 in the $1^{\text {st }}$ PA of avian and frog embryos leads to transformation of first arch skeletal elements such as Meckel's cartilage into second arch structures ${ }^{60} 61$. Collectively, this suggests that Hoxa2 is the primary determinant of $2^{\text {nd }} \mathrm{PA}$ identity. Interestingly, simultaneous inactivation of the entire Hoxa cluster in all pharyngeal arch NCC leads to the presence of supernumerary derivatives of the $1^{\text {st }} \mathrm{PA}$, such as incus, malleus and Meckel's cartilage throughout the entire pharyngeal region ${ }^{62}$. Thus all of the PAs may have the potency to form $1^{\text {st }}$ PA derivatives, however, Hox genes are incompatible with jaw formation as they inhibit the development of $1^{\text {st }} \mathrm{PA}$ characteristics. This implies that the identity of the $1^{\text {st }} \mathrm{PA}$ represents a $\mathrm{Dlx}$ dependent/ Hox independent default state. Furthermore, perhaps evolution the pharyngeal 
arches commenced with a uniform default $1^{\text {st }}$ PA identity, with different groups of $H o x$ genes subsequently providing identity to each of the more posterior regions of the head and neck.

Consistent with this idea, Hoxa 3 appears to be important for $3^{\text {rd }}$ PA dentity ${ }^{63}$. Hoxa 3 null mutant mice fail to form the buds of thymus and parathyroid and develop an impaired carotid artery system ${ }^{64}$. The thyroid defects seen in Hoxa 3 single mutants are exacerbated in double mutants with either Hoxb3 or Hoxd 3 paralogs. The removal of one functional copy of Hoxa 3 from the Hoxb3, Hoxd3 double mutants (Hoxa3 +/-, Hoxb3-/-, Hoxd3-/-) results in the failure of the thymus and parathyroid glands to migrate to their normal positions in the throat. Thus the Hox group 3 genes have overlapping functions in development of the pharyngeal organ primordia, structures that are derived from the $3^{\text {rd }}$ and $4^{\text {th }}$ PA pouches ${ }^{65}$.

RA is a well-known regulator of Hox gene activity and mechanistically this is achieved through the presence of retinoic acid response elements (RARE) in the promoter regions of many Hox genes ${ }^{66}$. In the presence of RA, the retinoid receptors, RARs and RXRs form heterodimers that bind RAREs to regulate Hox gene activity ${ }^{67}$. Interestingly, RA also influences Dlx gene activity as well. E8.5 mouse embryos treated transiently with exogenous RA, phenocopy the lower jaw to upper jaw transformations observed in Edn1-/- and Dlx5/6-/- mutant mice. RA does not directly affect the migration or survival of $\mathrm{NCC}^{68}$, rather exogenous RA represses Endothelin signaling in the $1^{\text {st }} \mathrm{PA}$, which as described above is a direct regulator of $D l x$ gene activity ${ }^{69}$. Thus RA signaling is a critical mediator of pharyngeal segmentation and patterning through its roles in endoderm development and in the regulation of $D l x / H o x$ gene activity.

\section{Conclusion}

The pharyngeal apparatus is essential for the dual functions of respiration and feeding. It is formed from a reiterated series of outgrowths on the side of the embryo termed pharyngeal arches (PAs), whose anatomical composition is highly conserved throughout evolution. Each PA is composed of two epithelia, the endoderm and ectoderm that together line a mesenchymal core composed solely of mesoderm in invertebrate embryos, or mesoderm and NCC in vertebrate embryos. These three germ layers, endoderm, mesoderm and ectoderm, as well as the NCC, sometimes called the 4th germ layer, are responsible for establishment of the skeleton, musculature nervous system and vasculature of the vertebrate face, neck and upper thorax.

The endoderm plays a critical role in PA segmentation and patterning. Through migration and a process call out-pocketing, the endoderm evaginates to contact the ectoderm and in doing so forms the pharyngeal pouches which separate the individual PAs. Thus the pharyngeal endoderm is essential for pharyngeal segmentation and this process is regulated primarily by Fgf signaling. Furthermore, the endoderm is a source of signals that direct the differentiation of PA neural crest cells into cartilage and this includes Fgf, RA and Tbx1 signaling. 
The number of PAs varies between species and the aquatic to land dwelling lifestyle changes that were accompanied by gill to lung transitions may be associated with the general decrease in PA number in reptiles and mammals compared to fish. However, the molecular regulation of anterioposterior and dorsoventral PA identity and polarity has been largely conserved. The $1^{\text {st }} \mathrm{PA}$, is regulated by $D l x$ gene activity, with $D l x 5 / 6$ playing a primary role in distinguishing mandibular identity (lower jaw) from a potentially default maxillary identity (upper jaw). Interestingly, Hox genes which are not expressed in the $1^{\text {st }}$ PA, are actually incompatible with jaw formation. Instead distinct groups of Hox genes govern the identity and patterning of the more caudal $2^{\text {nd }}$ to $6^{\text {th }}$ PAs, with Hoxa 2 being the primary determinant of $2^{\text {nd }}$ PA. Therefore a combinatorial code of Dlx and Hox genes is critical for establishing the identity and subsequent development of individual PAs during formation of the pharyngeal apparatus.

The pathways described in this review are conserved from mouse to jawless species such as lampreys. But the molecular mechanisms underlying the species-specific shape of bones of the face and neck are poorly understood. The signals emanating from the endoderm, ectoderm or mesoderm that control proliferation, differentiation, migration, morphology or survival of NCC remain to be fully elucidated. Approximately, one-third of congenital malformations affect the head region, and the identification of novel genes that intrinsically or extrinsically regulate NCC development, could further the development of therapeutic avenues for treating syndromes affecting the pharyngeal apparatus.

In summary, the development of the pharyngeal apparatus is a complex process that relies on precise tissue interactions and numerous distinct signaling pathways for its normal development. This complexity has facilitated vertebrate evolution, but is also prone to perturbation and the pathogenesis of congenital anomalies of the head and neck. Therefore it is important to continue to strengthen our understanding of the molecular mechanism and cellular processes that govern the establishment, segmentation and differentiation of the pharyngeal arches during formation of the pharyngeal apparatus.

\section{Acknowledgments}

We are extremely grateful to Mark Miller for artistic illustrations and also to Dr Shachi Bhatt and Dr Margot Leroux-Berger for contributing to the pictures in Figure 3. Research in the Trainor laboratory is supported by the Stowers Institute for Medical Research and the National Institute for Dental and Craniofacial Research (DE 016082).

\section{References}

1. Jones NC, Trainor PA. The therapeutic potential of stem cells in the treatment of craniofacial abnormalities. Expert Opin Biol Ther. 2004; 4:645-657. [PubMed: 15155156]

2. Scambler PJ. The 22q11 deletion syndromes. Hum Mol Genet. 2000; 9:2421-2426. [PubMed: 11005797]

3. Walker MB, Trainor PA. Craniofacial malformations: intrinsic vs extrinsic neural crest cell defects in Treacher Collins and 22q11 deletion syndromes. Clin Genet. 2006; 69:471-479. [PubMed: 16712696]

4. Sperber GH. Craniofacial development. 2001

5. Le Douarin NMK. The Neural Crest. 1999 
6. Jiang X, Iseki S, Maxson RE, Sucov HM, Morriss-Kay GM. Tissue origins and interactions in the mammalian skull vault. Dev Biol. 2002; 241:106-116. [PubMed: 11784098]

7. Yamauchi Y, Abe K, Mantani A, Hitoshi Y, Suzuki M, Osuzu F, Kuratani S, Yamamura K. A novel transgenic technique that allows specific marking of the neural crest cell lineage in mice. Dev Biol. 1999; 212:191-203. [PubMed: 10419695]

8. Jiang X, Rowitch DH, Soriano P, McMahon AP, Sucov HM. Fate of the mammalian cardiac neural crest. Development. 2000; 127:1607-1616. [PubMed: 10725237]

9. Chai Y, Jiang X, Ito Y, Bringas P Jr, Han J, Rowitch DH, Soriano P, McMahon AP, Sucov HM. Fate of the mammalian cranial neural crest during tooth and mandibular morphogenesis.

Development. 2000; 127:1671-1679. [PubMed: 10725243]

10. Noden DM. The role of the neural crest in patterning of avian cranial skeletal, connective, and muscle tissues. Dev Biol. 1983; 96:144-165. [PubMed: 6825950]

11. Schilling TF, Kimmel CB. Segment and cell type lineage restrictions during pharyngeal arch development in the zebrafish embryo. Development. 1994; 120:483-494. [PubMed: 8162849]

12. Lee SH, Bedard O, Buchtova M, Fu K, Richman JM. A new origin for the maxillary jaw. Dev Biol. 2004; 276:207-224. [PubMed: 15531375]

13. Helms JA, Schneider RA. Cranial skeletal biology. Nature. 2003; 423:326-331. [PubMed: 12748650]

14. Hiruma T, Hirakow R. Formation of the pharyngeal arch arteries in the chick embryo. Observations of corrosion casts by scanning electron microscopy. Anat Embryol (Berl). 1995; 191:415-423. [PubMed: 7625612]

15. Le Lievre CS, Le Douarin NM. Mesenchymal derivatives of the neural crest: analysis of chimaeric quail and chick embryos. J Embryol Exp Morphol. 1975; 34:125-154. [PubMed: 1185098]

16. Ali MM, Farooqui FA, Sohal GS. Ventrally emigrating neural tube cells contribute to the normal development of heart and great vessels. Vascul Pharmacol. 2003; 40:133-140. [PubMed: 12646402]

17. Mikawa T, Gourdie RG. Pericardial mesoderm generates a population of coronary smooth muscle cells migrating into the heart along with ingrowth of the epicardial organ. Dev Biol. 1996; 174:221-232. [PubMed: 8631495]

18. Hiruma T, Nakajima Y, Nakamura H. Development of pharyngeal arch arteries in early mouse embryo. J Anat. 2002; 201:15-29. [PubMed: 12171473]

19. Holland LZ, Kene M, Williams NA, Holland ND. Sequence and embryonic expression of the amphioxus engrailed gene (AmphiEn): the metameric pattern of transcription resembles that of its segment-polarity homolog in Drosophila. Development. 1997; 124:1723-1732. [PubMed: 9165120]

20. Rychel AL, Smith SE, Shimamoto HT, Swalla BJ. Evolution and development of the chordates: collagen and pharyngeal cartilage. Mol Biol Evol. 2006; 23:541-549. [PubMed: 16280542]

21. Yao T, Ohtani K, Kuratani S, Wada H. Development of lamprey mucocartilage and its dorsalventral patterning by endothelin signaling, with insight into vertebrate jaw evolution. J Exp Zool B Mol Dev Evol. 2011; 316:339-346. [PubMed: 21351246]

22. Depew MJ, Compagnucci C. Tweaking the hinge and caps: testing a model of the organization of jaws. J Exp Zool B Mol Dev Evol. 2008; 310:315-335. [PubMed: 18027841]

23. Sienknecht UJ. Developmental origin and fate of middle ear structures. Hear Res. 2013; 301:1926. [PubMed: 23396272]

24. Gillis JA, Modrell MS, Baker CV. Developmental evidence for serial homology of the vertebrate jaw and gill arch skeleton. Nat Commun. 2013; 4:1436. [PubMed: 23385581]

25. Veitch E, Begbie J, Schilling TF, Smith MM, Graham A. Pharyngeal arch patterning in the absence of neural crest. Curr Biol. 1999; 9:1481-1484. [PubMed: 10607595]

26. Gavalas A, Trainor P, Ariza-McNaughton L, Krumlauf R. Synergy between Hoxa1 and Hoxb1: the relationship between arch patterning and the generation of cranial neural crest. Development. 2001; 128:3017-3027. [PubMed: 11532923]

27. Piotrowski T, Ahn DG, Schilling TF, Nair S, Ruvinsky I, Geisler R, Rauch GJ, Haffter P, Zon LI, Zhou Y, et al. The zebrafish van gogh mutation disrupts tbx 1, which is involved in the DiGeorge deletion syndrome in humans. Development. 2003; 130:5043-5052. [PubMed: 12952905] 
28. Jerome LA, Papaioannou VE. DiGeorge syndrome phenotype in mice mutant for the T-box gene, Tbx1. Nat Genet. 2001; 27:286-291. [PubMed: 11242110]

29. Couly G, Creuzet S, Bennaceur S, Vincent C, Le Douarin NM. Interactions between Hox-negative cephalic neural crest cells and the foregut endoderm in patterning the facial skeleton in the vertebrate head. Development. 2002; 129:1061-1073. [PubMed: 11861488]

30. Vermot J, Niederreither K, Garnier JM, Chambon P, Dolle P. Decreased embryonic retinoic acid synthesis results in a DiGeorge syndrome phenotype in newborn mice. Proc Natl Acad Sci U S A. 2003; 100:1763-1768. [PubMed: 12563036]

31. Sandell LL, Sanderson BW, Moiseyev G, Johnson T, Mushegian A, Young K, Rey JP, Ma JX, Staehling-Hampton K, Trainor PA. RDH10 is essential for synthesis of embryonic retinoic acid and is required for limb, craniofacial, and organ development. Genes Dev. 2007; 21:1113-1124. [PubMed: 17473173]

32. Roberts C, Ivins SM, James CT, Scambler PJ. Retinoic acid down-regulates Tbx1 expression in vivo and in vitro. Dev Dyn. 2005; 232:928-938. [PubMed: 15736167]

33. Kopinke D, Sasine J, Swift J, Stephens WZ, Piotrowski T. Retinoic acid is required for endodermal pouch morphogenesis and not for pharyngeal endoderm specification. Dev Dyn. 2006; 235:26952709. [PubMed: 16871626]

34. Crump JG, Maves L, Lawson ND, Weinstein BM, Kimmel CB. An essential role for Fgfs in endodermal pouch formation influences later craniofacial skeletal patterning. Development. 2004; 131:5703-5716. [PubMed: 15509770]

35. Trokovic N, Trokovic R, Mai P, Partanen J. Fgfr1 regulates patterning of the pharyngeal region. Genes Dev. 2003; 17:141-153. [PubMed: 12514106]

36. Jandzik D, Hawkins MB, Cattell MV, Cerny R, Square TA, Medeiros DM. Roles for FGF in lamprey pharyngeal pouch formation and skeletogenesis highlight ancestral functions in the vertebrate head. Development. 2014; 141:629-638. [PubMed: 24449839]

37. Choe CP, Collazo A, Trinh le A, Pan L, Moens CB, Crump JG. Wnt-dependent epithelial transitions drive pharyngeal pouch formation. Dev Cell. 2013; 24:296-309. [PubMed: 23375584]

38. Sumiyama K, Irvine SQ, Ruddle FH. The role of gene duplication in the evolution and function of the vertebrate Dlx/distal-less bigene clusters. J Struct Funct Genomics. 2003; 3:151-159. [PubMed: 12836694]

39. Qiu M, Bulfone A, Martinez S, Meneses JJ, Shimamura K, Pedersen RA, Rubenstein JL. Null mutation of Dlx-2 results in abnormal morphogenesis of proximal first and second branchial arch derivatives and abnormal differentiation in the forebrain. Genes Dev. 1995; 9:2523-2538. [PubMed: 7590232]

40. Qiu M, Bulfone A, Ghattas I, Meneses JJ, Christensen L, Sharpe PT, Presley R, Pedersen RA, Rubenstein JL. Role of the Dlx homeobox genes in proximodistal patterning of the branchial arches: mutations of Dlx-1, Dlx-2, and Dlx-1 and -2 alter morphogenesis of proximal skeletal and soft tissue structures derived from the first and second arches. Dev Biol. 1997; 185:165-184. [PubMed: 9187081]

41. Depew MJ, Liu JK, Long JE, Presley R, Meneses JJ, Pedersen RA, Rubenstein JL. Dlx5 regulates regional development of the branchial arches and sensory capsules. Development. 1999; 126:3831-3846. [PubMed: 10433912]

42. Depew MJ, Lufkin T, Rubenstein JL. Specification of jaw subdivisions by Dlx genes. Science. 2002; 298:381-385. [PubMed: 12193642]

43. Beverdam A, Merlo GR, Paleari L, Mantero S, Genova F, Barbieri O, Janvier P, Levi G. Jaw transformation with gain of symmetry after Dlx5/Dlx6 inactivation: mirror of the past? Genesis. 2002; 34:221-227. [PubMed: 12434331]

44. Morasso MI, Grinberg A, Robinson G, Sargent TD, Mahon KA. Placental failure in mice lacking the homeobox gene Dlx3. Proc Natl Acad Sci U S A. 1999; 96:162-167. [PubMed: 9874789]

45. Nataf V, Grapin-Botton A, Champeval D, Amemiya A, Yanagisawa M, Le Douarin NM. The expression patterns of endothelin-A receptor and endothelin 1 in the avian embryo. Mech Dev. 1998; 75:145-149. [PubMed: 9739130]

46. Clouthier DE, Garcia E, Schilling TF. Regulation of facial morphogenesis by endothelin signaling: insights from mice and fish. Am J Med Genet A. 2010; 152A:2962-2973. [PubMed: 20684004] 
47. Kurihara Y, Kurihara H, Suzuki H, Kodama T, Maemura K, Nagai R, Oda H, Kuwaki T, Cao WH, Kamada N, et al. Elevated blood pressure and craniofacial abnormalities in mice deficient in endothelin-1. Nature. 1994; 368:703-710. [PubMed: 8152482]

48. Ruest LB, Xiang X, Lim KC, Levi G, Clouthier DE. Endothelin-A receptor-dependent and independent signaling pathways in establishing mandibular identity. Development. 2004; 131:4413-4423. [PubMed: 15306564]

49. Kempf H, Linares C, Corvol P, Gasc JM. Pharmacological inactivation of the endothelin type A receptor in the early chick embryo: a model of mispatterning of the branchial arch derivatives. Development. 1998; 125:4931-4941. [PubMed: 9811577]

50. Sato T, Kurihara Y, Asai R, Kawamura Y, Tonami K, Uchijima Y, Heude E, Ekker M, Levi G, Kurihara H. An endothelin-1 switch specifies maxillomandibular identity. Proc Natl Acad Sci U S A. 2008; 105:18806-18811. [PubMed: 19017795]

51. Vieux-Rochas M, Mantero S, Heude E, Barbieri O, Astigiano S, Couly G, Kurihara H, Levi G, Merlo GR. Spatio-temporal dynamics of gene expression of the Edn1-Dlx5/6 pathway during development of the lower jaw. Genesis. 2010; 48:262-373. [PubMed: 20333701]

52. Yanagisawa H, Clouthier DE, Richardson JA, Charite J, Olson EN. Targeted deletion of a branchial arch-specific enhancer reveals a role of dHAND in craniofacial development. Development. 2003; 130:1069-1078. [PubMed: 12571099]

53. Barron F, Woods C, Kuhn K, Bishop J, Howard MJ, Clouthier DE. Downregulation of Dlx5 and Dlx6 expression by Hand2 is essential for initiation of tongue morphogenesis. Development. 2011; 138:2249-2259. [PubMed: 21558373]

54. Rieder MJ, Green GE, Park SS, Stamper BD, Gordon CT, Johnson JM, Cunniff CM, Smith JD, Emery SB, Lyonnet S, et al. A human homeotic transformation resulting from mutations in PLCB4 and GNAI3 causes auriculocondylar syndrome. Am J Hum Genet. 2012; 90:907-914. [PubMed: 22560091]

55. Trainor PA, Krumlauf R. Hox genes, neural crest cells and branchial arch patterning. Curr Opin Cell Biol. 2001; 13:698-705. [PubMed: 11698185]

56. Hunt P, Krumlauf R. Hox genes coming to a head. Curr Biol. 1991; 1:304-306. [PubMed: 15336105]

57. Hunt P, Krumlauf R. Deciphering the Hox code: clues to patterning branchial regions of the head. Cell. 1991; 66:1075-1078. [PubMed: 1680562]

58. Rijli FM, Mark M, Lakkaraju S, Dierich A, Dolle P, Chambon P. A homeotic transformation is generated in the rostral branchial region of the head by disruption of Hoxa-2, which acts as a selector gene. Cell. 1993; 75:1333-1349. [PubMed: 7903601]

59. Gendron-Maguire M, Mallo M, Zhang M, Gridley T. Hoxa-2 mutant mice exhibit homeotic transformation of skeletal elements derived from cranial neural crest. Cell. 1993; 75:1317-1331. [PubMed: 7903600]

60. Grammatopoulos GA, Bell E, Toole L, Lumsden A, Tucker AS. Homeotic transformation of branchial arch identity after Hoxa2 overexpression. Development. 2000; 127:5355-5365. [PubMed: 11076757]

61. Pasqualetti M, Ori M, Nardi I, Rijli FM. Ectopic Hoxa2 induction after neural crest migration results in homeosis of jaw elements in Xenopus. Development. 2000; 127:5367-5378. [PubMed: 11076758]

62. Minoux M, Antonarakis GS, Kmita M, Duboule D, Rijli FM. Rostral and caudal pharyngeal arches share a common neural crest ground pattern. Development. 2009; 136:637-645. [PubMed: 19168678]

63. Chisaka O, Capecchi MR. Regionally restricted developmental defects resulting from targeted disruption of the mouse homeobox gene hox-1.5. Nature. 1991; 350:473-479. [PubMed: 1673020]

64. Kameda Y. Hoxa3 and signaling molecules involved in aortic arch patterning and remodeling. Cell Tissue Res. 2009; 336:165-178. [PubMed: 19290546]

65. Manley NR, Capecchi MR. Hox group 3 paralogs regulate the development and migration of the thymus, thyroid, and parathyroid glands. Dev Biol. 1998; 195:1-15. [PubMed: 9520319]

66. Marshall H, Morrison A, Studer M, Popperl H, Krumlauf R. Retinoids and Hox genes. FASEB J. 1996; 10:969-978. [PubMed: 8801179] 
67. Nagpal S, Friant S, Nakshatri H, Chambon P. RARs and RXRs: evidence for two autonomous transactivation functions (AF-1 and AF-2) and heterodimerization in vivo. EMBO J. 1993; 12:2349-2360. [PubMed: 8389696]

68. Lee YM, Osumi-Yamashita N, Ninomiya Y, Moon CK, Eriksson U, Eto K. Retinoic acid stagedependently alters the migration pattern and identity of hindbrain neural crest cells. Development. 1995; 121:825-837. [PubMed: 7720586]

69. Vieux-Rochas M, Coen L, Sato T, Kurihara Y, Gitton Y, Barbieri O, Le Blay K, Merlo G, Ekker M, Kurihara H, et al. Molecular dynamics of retinoic acid-induced craniofacial malformations: implications for the origin of gnathostome jaws. PLoS One. 2007; 2:e510. [PubMed: 17551590] 


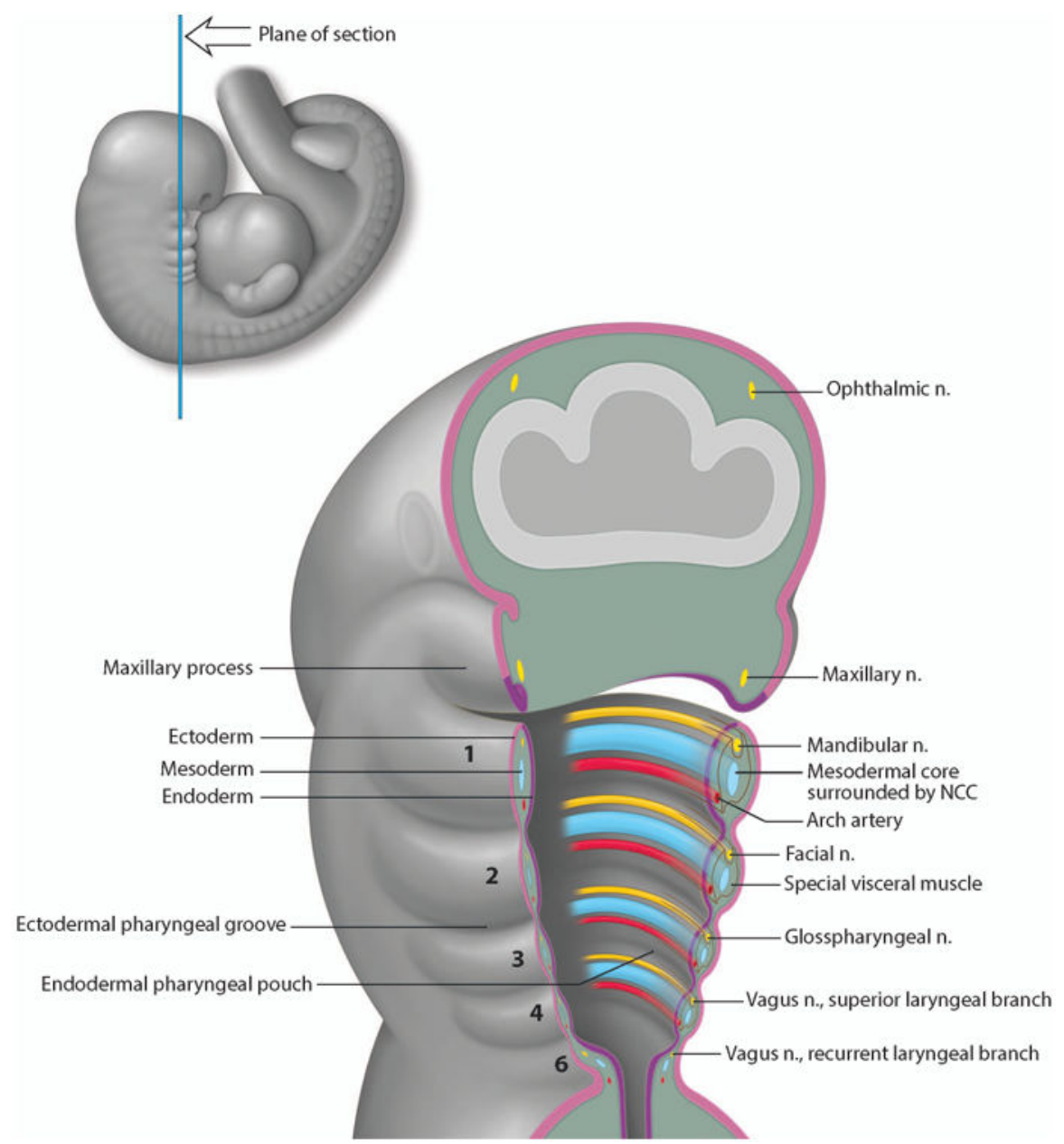

Figure 1. Structural Organization of the Pharyngeal Arches in a Human Embryo Schematic illustration of the internal organization of the developing PAs. Each PA is numbered from 1 to 6 . PAs are lined externally by ectoderm in pink and internally by endoderm in purple. Inside, each PA is a mesenchymal core (blue) composed of mesoderm cells surrounded by NCC cells alongside the nerve (yellow) and blood vessel (red) components. 

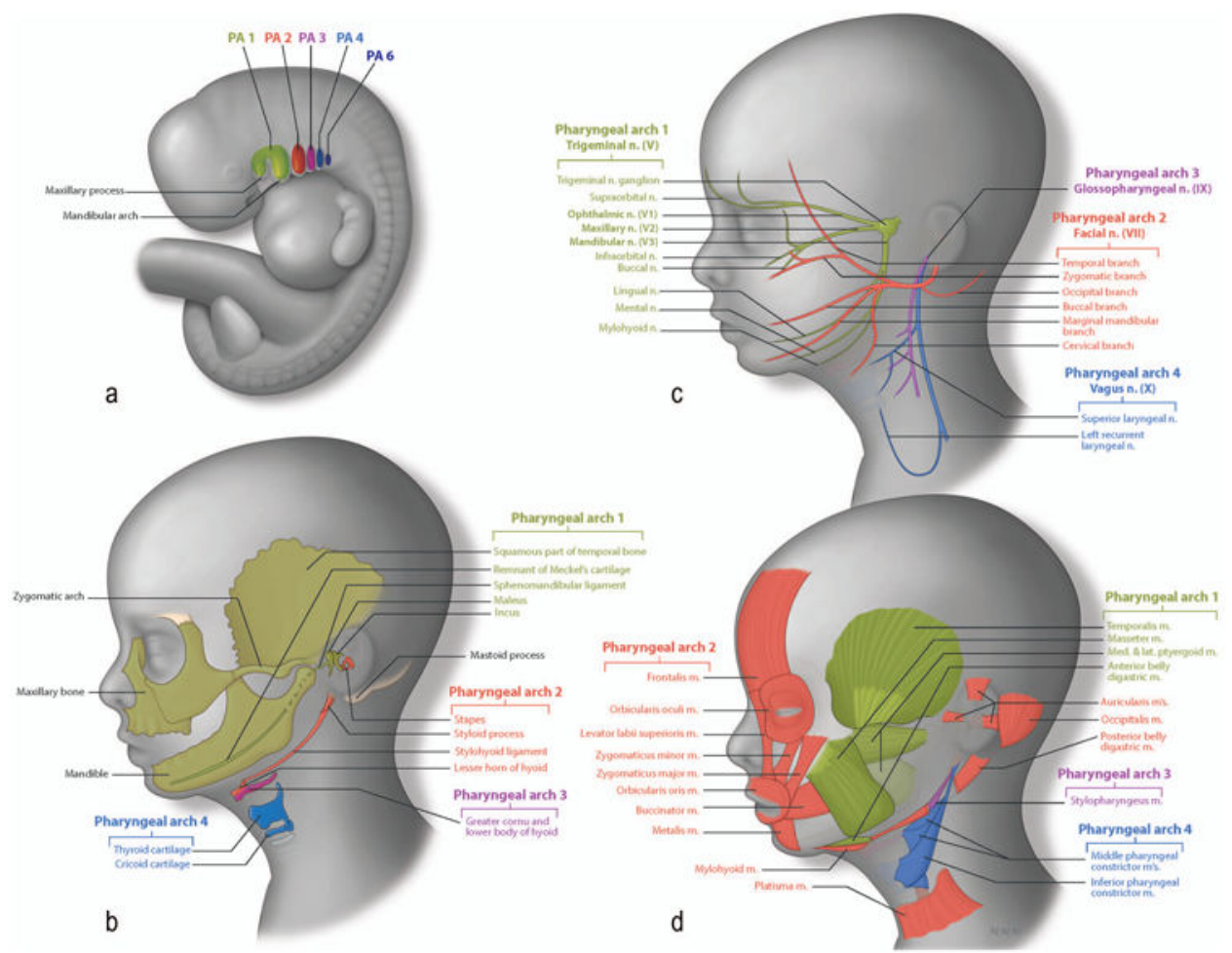

Figure 2. Pharyngeal Arch Differentiation

Figure 2a: Schematic illustration of the pharyngeal region of a human embryo. Figure $2 b$ : Skeletal derivatives of the NCC. Bones of the face are formed by two ossification processes. Endochondral bones are formed via a cartilage template and include the maleus (from Meckel's cartilage), and the incus (from maxillary cartilage) from the $1^{\text {st }} \mathrm{PA}$ (green). The stapes, the styloid process and lesser horn of hyoid (from Reichter's cartilage) come from the $2^{\text {nd }}$ PA (red). Dermal bone formation consists of direct ossification of the NCC without a cartilage intermediate. Dermal elements include the squamous part of the temporal bone, the zygomatic, the maxillary bone and the mandible, which are derived from $1^{\text {st }} \mathrm{PA}$ (green).

Figure 2c: Neural derivatives of the NCC The trigeminal nerve (V) comprises 3 subdivisions: the ophthalmic nerve, the maxillary nerve and the mandibular nerve and develops in association with the $1^{\text {st }} \mathrm{PA}$, (green). The facial nerve invades the $2^{\text {nd }} \mathrm{PA}$, (red). The glossopharyngeal invades the $3^{\text {rd }} \mathrm{PA}$, (purple) and the vagus nerve the $4^{\text {th }} \mathrm{PA}$, (dark blue). Figure 2d: Muscular derivatives of the mesoderm. Muscles (green) of mastication are derived from mesoderm of the $1^{\text {st }} \mathrm{PA}$. Muscles of facial expression (red) are derived from $2^{\text {nd }}$ PA mesoderm. The stylopharyngeus (purple) is the only muscle that is derived from the $3^{\text {rd }}$ PA mesoderm. The external muscles of the pharynx (blue) are derived from $4^{\text {th }} \mathrm{PA}$ mesoderm. 

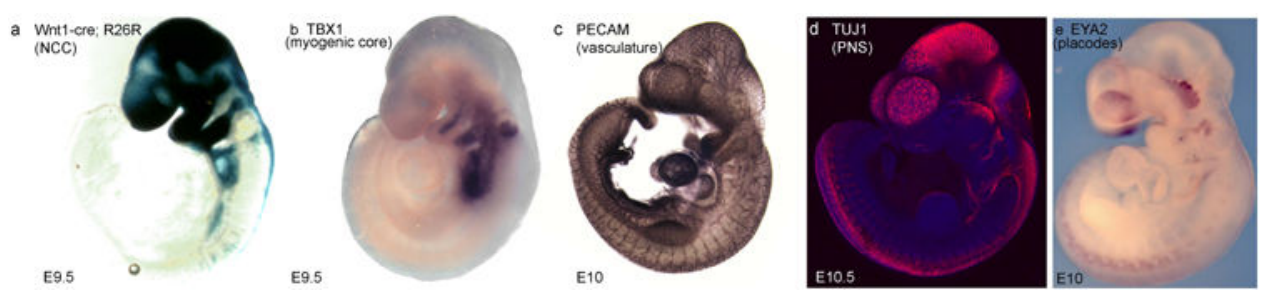

Figure 3. Establishment of the musculature, vasculature, and PNS of the face in mouse embryo a. LacZ staining marking NCC. b. tbxl in situ hybridization showing the myogenic core of each PA. c. Pecam immunostaining marking endothelial cells of the developing vasculature. d.Tuj1 immunostaining marking NCC and placode-derived neurons, e. Eya2 in situ hybridization, delimiting the cranial placodes. 


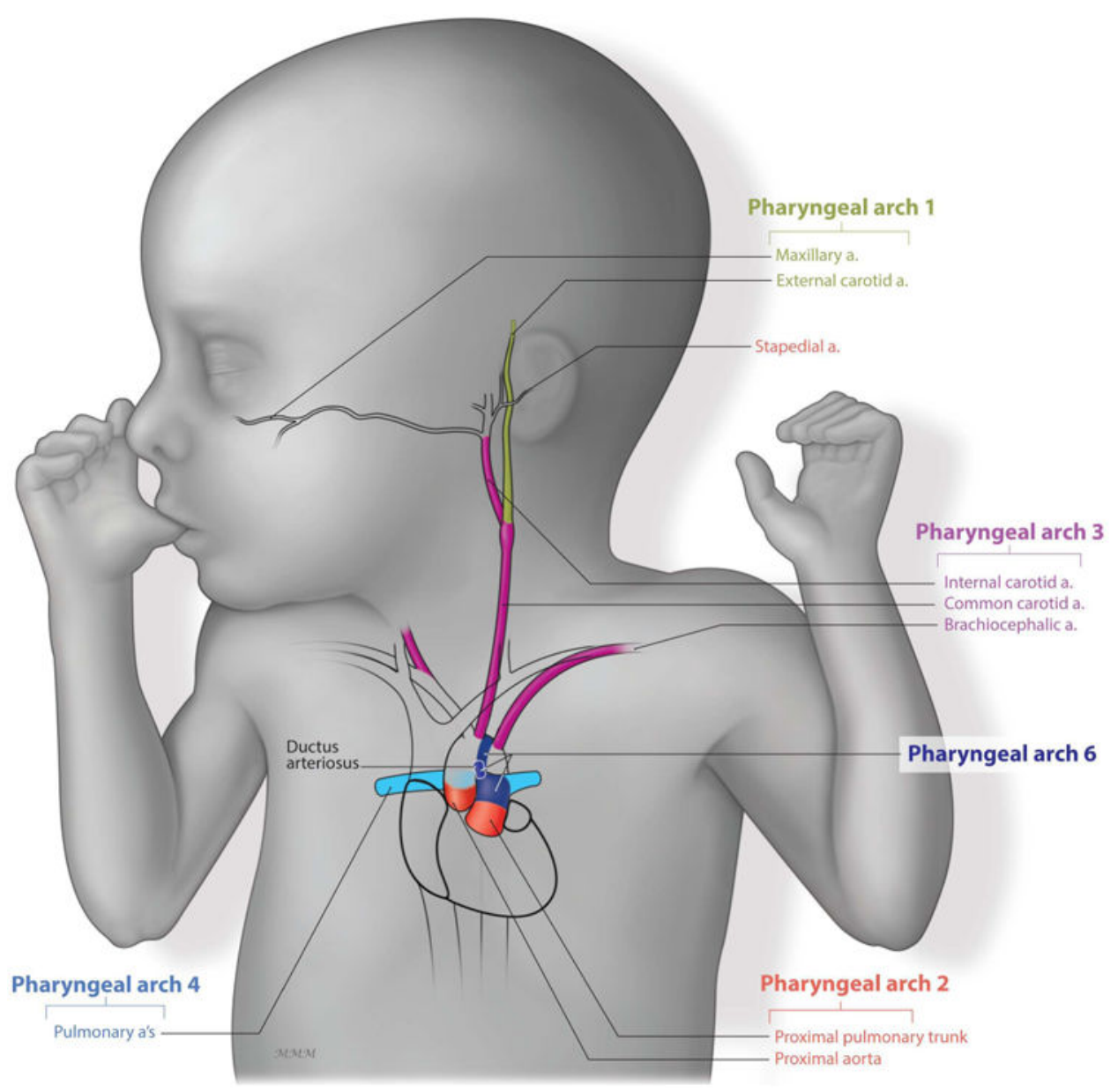

Figure 4. Pharyngeal Arch Vascular Patterning

The maxillary artery (green) is derived from the $1^{\text {st }}$ PAA. The stapedial (red) is derived from the $2^{\text {nd }}$ PAA. The carotid system (purple) derives from the 3 rd PAA. The left $4^{\text {th }}$ PAA gives rise to the aortic arch while the right PAA gives rise to the subclavian artery and contributes to the pulmonary arteries (light blue). Finally, the $6^{\text {th }}$ PAA give rise to the ductus arteriosus (dark blue) and the pulmonary arteries (light blue). 


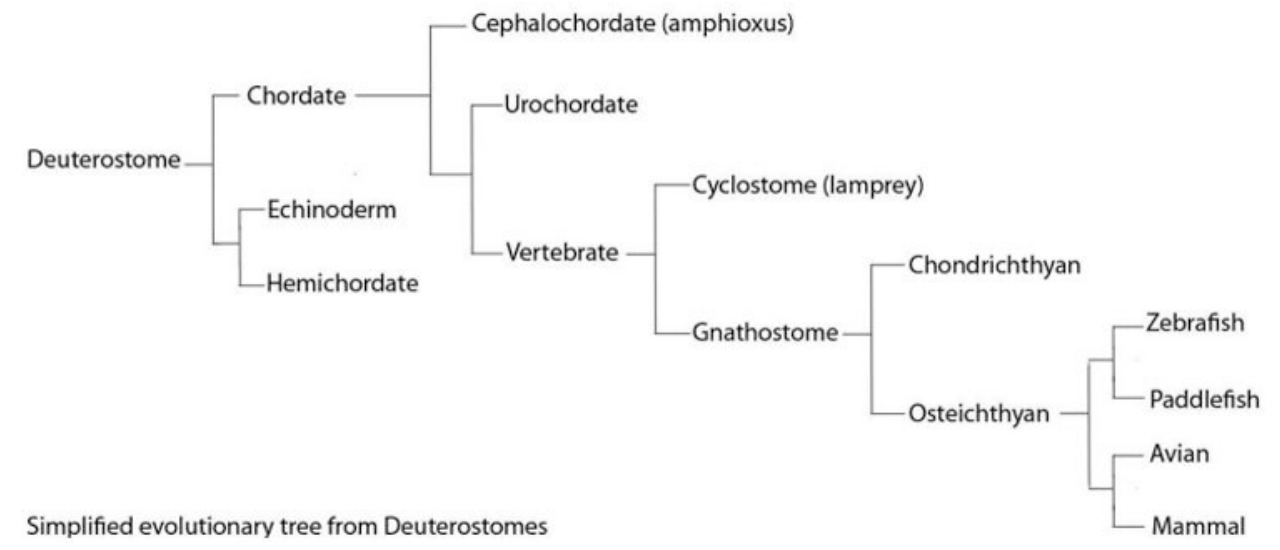

Figure 5. Evolutionary Cladogram

Evolutionary tree showing the classification of species from deuterostomes to mammals. NCCs appear during the transition to vertebrates. 


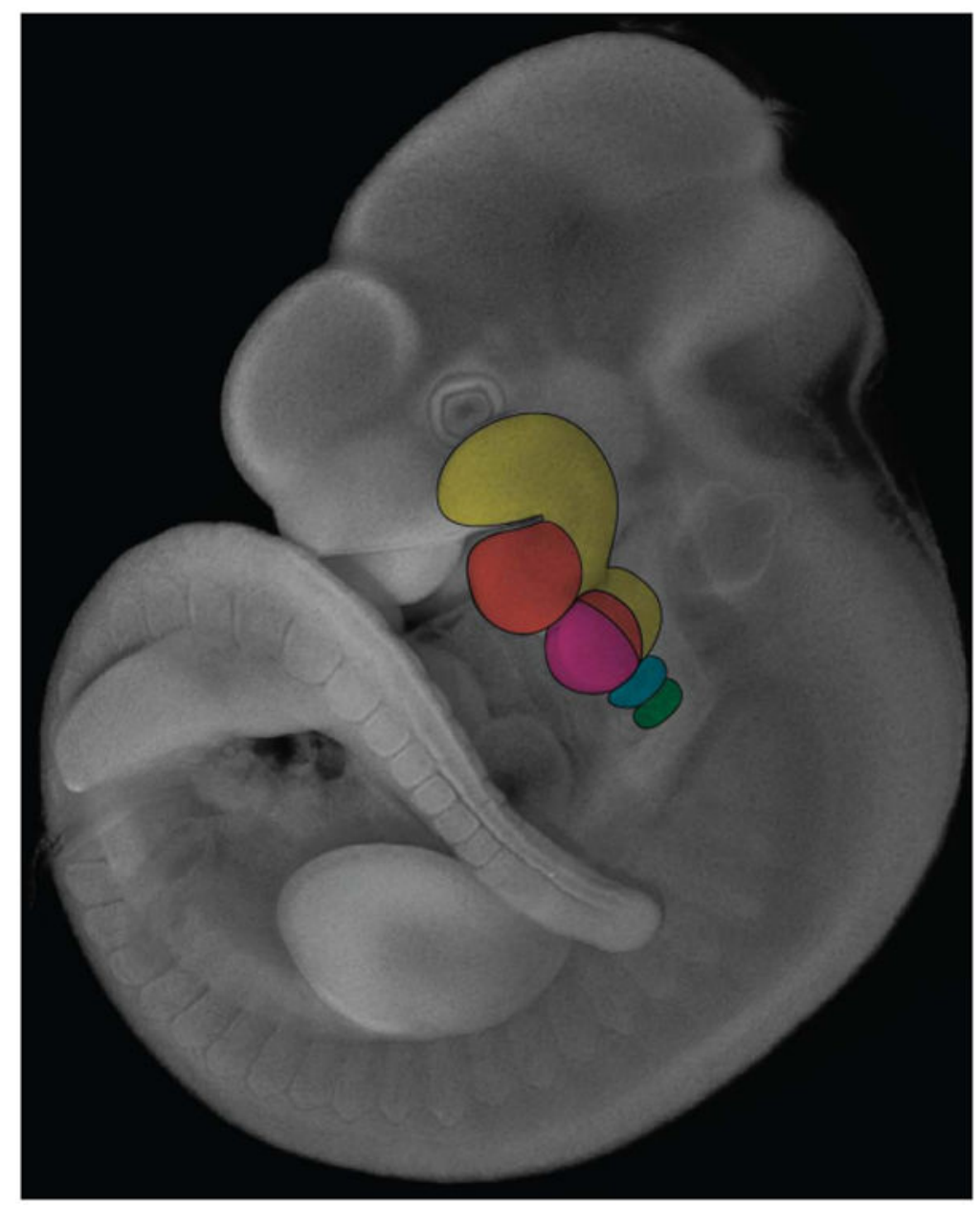

Figure 6. Dlx and Hox gene control of pharyngeal patterning

Dapi staining of E10.5 mouse embryo. Expression domain of Dlx1 and Dlx2 (yellow) in the $1^{\text {st }}$ and $2^{\text {nd }}$ PA. Nested expression of Dlx 5 and Dlx6 (orange) within the Dlx 1 and $D l x 2$ domains of expression. Hox 2 group genes are expressed in the $2^{\text {nd }} \mathrm{PA}$ (pink) and more posterior Pas, while Hox group 3 (blue) and Hox group 4 (green) genes are expressed in the $3^{\text {rd }}$ and $4^{\text {th }}$ PAs resepectively. 


\section{Table 1}

\section{Skeletal derivatives of the PAs}

\begin{tabular}{|l|c|c|}
\hline PA & Endochondral bone (ossification of NCC-derived cartilaginous intermediate) & Dermal bones (direct ossification of NCC) \\
\hline 1 & From Meckel's cartilage: & Maxilla \\
& - malleus & Zygomatic \\
& From maxillary cartilage: & Squamous portion of temporal bone \\
& $\quad$ Incus & \\
\hline 2 & From Reichert's cartilage: & \\
& $\quad$ Stapes & \\
\hline 3 & Styloid process & \\
\hline 4 & Upper part of the hyoid bone & \\
\hline 6 & -Laryngeal cartilage & \\
\hline
\end{tabular}




\section{Table 2}

\section{Vascular derivatives of the PAs}

\begin{tabular}{|l|l|}
\hline Pharyngeal arch Arteries & Arteries in adult \\
\hline $1^{\text {st }} \mathrm{PA}$ & Maxillary artery (small portion) \\
\hline $2^{\text {nd }} \mathrm{PA}$ & Stapedial artery \\
\hline $3^{\text {rd }} \mathrm{PA}$ & Common carotid artery First part of the internal carotid artery \\
\hline $4^{\text {th }} \mathrm{PA}$ & $\begin{array}{l}\text { Left side: segment of the aortic arch artery between the common carotid and the left subclavian artery } \\
\text { Right side: proximal part of the right subclavian artery and the pulmonary arteries }\end{array}$ \\
\hline $6^{\text {th }} \mathrm{PA}$ & $\begin{array}{l}\text { Right side: disappears } \\
\text { Left side: Ductus arteriosus }\end{array}$ \\
\hline
\end{tabular}


Table 3

Muscle derivatives of the PAs and their innervation

\begin{tabular}{|c|c|c|}
\hline Pharyngeal arch & Muscle & Nerve \\
\hline $1^{\text {st }} \mathrm{PA}$ & $\begin{array}{ll}\text { Mastication: } \\
\text { - } & \text { masseter } \\
\text { - } & \text { temporalis } \\
\text { - } & \text { medial and lateral pterygoid } \\
\text { - } & \text { anterior belly of digastric muscle }\end{array}$ & Mandibular part of trigeminal (nerve V) \\
\hline $2^{\text {nd }} P A$ & $\begin{array}{ll}\text { - } & \text { Buccinator } \\
\text { - } & \text { Expression muscles }\end{array}$ & Facial (nerve VII) \\
\hline $3^{\text {rd }} \mathrm{PA}$ & Stylopharyngeus & Glossopharyngeal (nerve.IX) \\
\hline $4^{\text {th }} \mathrm{PA}$ & Constrictors of pharynx, cricothyroid levator veli palatine & Vagus (nerve $\mathrm{X}$ ) \\
\hline $6^{\text {th }} \mathrm{PA}$ & Intrinsic muscle of larynx & Vagus (nerve $\mathrm{X}$ ) \\
\hline
\end{tabular}


Table 4

\section{Derivatives of pouches and clefts}

\begin{tabular}{|l|l|l|l|}
\hline Endodermal pouch & Anatomical adult structure derivative & Ectodermal cleft & Anatomical adult structure derivative \\
\hline $1^{\text {st }}$ pouch & $\begin{array}{c}\text { Tubotympanic recessthat leads to: } \\
\text { epithelium of tympanic cavity } \\
\text { eustachian tube }\end{array}$ & $1^{\text {st }}$ cleft & External auditory canal \\
\hline $2^{\text {nd }}$ pouch & Palatin tonsil epithelium & $2^{\text {nd }}$ cleft & \\
\hline $3^{\text {rd }}$ pouch & & $3^{\text {rd }}$ cleft & \\
\hline $4^{\text {th }}$ pouch & Thyroid and thymus Ultimobranchial body & $4^{\text {th }}$ cleft & \\
\hline $6^{\text {th }}$ pouch & Ultimobranchial body & $6^{\text {th }}$ cleft & \\
\hline
\end{tabular}




\section{Table 5}

Mouse mutants and their phenotypes

\begin{tabular}{|c|c|c|}
\hline genes & phenotype & references \\
\hline Dlxl-/- & Defects of stapes and alisphenoid bones & Qiu et at., 1997 \\
\hline Dlx2-/- & Defects in proximal elements of $1^{\text {st }}$ and $2^{\text {nd }} P A s$ & Qiu et at., 1995 \\
\hline Dlxl/2-/- & Defects of proximal elements of $1^{\text {st }}$ and $2^{\text {nd }}$ PAs & Qiu et at., 1997 \\
\hline Dlx5-/- & Lower jaw shortened & Depew et al., 1999 \\
\hline Dlx5/6-/- & Lower jaw transformed into upper jaw & Beverdam et al., 2002 \\
\hline Edn1-/- & Small lower jaw (absence of Meckel's cartilage) & Kurihara et al., 1994 \\
\hline$E d n 1$ overexpression & Upper jaw transformed into lower jaw & Sato et al., 2008 \\
\hline Hand2 enhancer-/- & Mandibular hypoplasia & Yanagisawa et al., 2003 \\
\hline Hoxa2-/- & $2^{\text {nd }} \mathrm{PA}$ elements transformed into $1^{\mathrm{st}} \mathrm{PA}$ elements & Rijli et al., 1994 \\
\hline Hoxa 2 overexpression & $1^{\text {st }} \mathrm{PA}$ elements transformed into $2^{\text {nd }} \mathrm{PA}$ elements & Grammatopoulos et al., 2000 \\
\hline Нохаз-/- & Absence of thymus and parathyroid and impaired carotid artery system & $\begin{array}{l}\text { Manley et al., 1998; } \\
\text { Kameda et al., } 2009\end{array}$ \\
\hline
\end{tabular}

